\title{
Evaluating the Risk of Natural Gas Pipeline Operation Management in Intuitionistic Fuzzy Linguistic Environments
}

\author{
Ming Li $\mathbb{D}^{1},{ }^{1}$ Liangliang Liu $\left(\mathbb{D},{ }^{1,2}\right.$ Ying Li, ${ }^{1}$ and Yingcheng $\mathrm{Xu}^{3}$ \\ ${ }^{1}$ School of Business Administration, China University of Petroleum-Beijing, Beijing 102249, China \\ ${ }^{2}$ Kunlun Insurance Brokers Co., Ltd., Beijing 100033, China \\ ${ }^{3}$ China National Institute of Standardization, Beijing 100191, China
}

Correspondence should be addressed to Liangliang Liu; makeinnovations@foxmail.com

Received 2 March 2018; Revised 9 July 2018; Accepted 29 July 2018; Published 13 August 2018

Academic Editor: Emilio Jiménez Macías

Copyright (C) 2018 Ming Li et al. This is an open access article distributed under the Creative Commons Attribution License, which permits unrestricted use, distribution, and reproduction in any medium, provided the original work is properly cited.

\begin{abstract}
Natural gas pipeline has been regarded as the most cost effective and safest channel of gas transportation and has extraordinary strategic significance for the country. There is a need to control the risks during the operation so as to operate the pipeline safely and smoothly under the complicated business environment. In order to evaluate the risk of natural gas pipeline operation management, this paper proposed an approach to evaluate the risk of natural gas pipeline operation management in intuitionistic fuzzy linguistic environments. Firstly, the evaluation criteria of the risk of natural gas pipeline operation management are established from the strategic risk, market risk, financial risk, operation risk, and legal risk aspects. Then experts are invited to evaluate the risk level and the weight of criteria using the linguistic terms. Rating values with regard to the criteria are in linguistic forms; the linguistic terms are modeled with the intuitionistic fuzzy linguistic model. The linguistic ratings are aggregated as the final results. Finally, the example is given to illustrate the feasibility and practicability of the proposed method.
\end{abstract}

\section{Introduction}

Oil and gas are strategic to a country and play a crucial role in economic development [1]. Pipeline is regarded as the most cost effective and safest channel to transport the oil and gas from upstream oil field or port to the downstream users or refineries [2]. It will bring large scale of loss and chaos to the society if the pipeline is accidental malfunction. It is necessary for the pipeline operators to identify, eliminate, control, avoid, or transfer the risk in case of accident or enterprise operation break in the normal operation. Risk of pipeline operation becomes a hot topic among the international pipeline operation companies on how to ensure that the pipeline transportation is safe and effective [3-11]. Many studies of the risk of pipeline operation are conducted from various aspects. For example, the risk of operating cross-country petroleum pipelines in India is analyzed [3]. The project risks are analyzed and applied to an oil pipeline construction project in India [4]. The case of Savadkooh in Iran is studied for Pipeline risk assessment [5]. The emerging threats to natural gas pipeline systems after a natural disaster are detected [6]. The risk to the long gas and oil pipeline project in China caused by landslides during its construction is assessed [7]. Reliability and risk of a port oil pipeline transportation system in variable operation conditions are evaluated [8]. Urban natural gas pipeline networks are assessed from the qualitative aspects and the quantitative aspect [9]. The uncertainty involved in the pipeline risk assessment modeled with the fuzzy logic is developed [10]. The quantitative risk assessment for natural gas pipelines is proposed [11]. However, these researches put focus on the technical perspective but not the operation management perspective.

In order to resolve the problem, in this paper, we proposed the approach to the evaluation of the risk of natural gas pipeline operation management. Firstly, the evaluation criteria are established. The risks are identified from enterprise strategy, marketing, operation, finance, and law aspects. Since these risks are difficult to be measured quantitatively, the linguistic values of expert evaluation are preferred. Secondly, with intuitionistic fuzzy set [12-14], the method for dealing with the linguistic evaluation information is proposed. 
The structure of the rest of this paper is as follows: Section 2 reviews the intuitionistic fuzzy set. In the following section, the evaluation criteria are constructed. Section 4 presents the method to deal with linguistic information. Section 5 provides an illustrate example. The final section concludes the paper.

\section{Intuitionistic Fuzzy Sets}

Due to the complexity and uncertainty of candidates, some criteria are more suitable for evaluation in linguistic form. The linguistic terms are mostly modeled with triangular fuzzy number $[15,16]$. Afterwards, intuitionistic fuzzy sets are proposed to model the linguistic terms [17]. Compared with fuzzy sets which only consider the degree of membership, intuitionistic fuzzy sets is characterized by both a membership function and a nonmembership function and the sum of both values is allowed to be less than one [18]. It has been used such as in the area of search algorithm selection [19], Rural Logistics Center Location [20], information system project selection [21], and green supply chain [22]. In the following, intuitionistic fuzzy sets are reviewed briefly [17, 18, 23-25].

Definition 1 (see [17]). Let $X$ be a given finite set; then define an intuitionistic fuzzy set on $X$ as $A$.

$$
A=\left\{\left[x, \mu_{A}(x), v_{A}(x)\right] \mid x \in X\right\}
$$

in which $\mu_{A}: X \rightarrow[0,1]$ and $v_{A}: X \longrightarrow$ $[0,1]$ are, respectively, the membership function and the nonmembership function, with the condition $0 \leq \mu_{A}(x)+$ $v_{A}(x) \leq 1$.

In addition, $\pi_{A}(x)=1-\mu_{A}(x)-v_{A}(x)$ represents the intuitionistic fuzzy index or hesitancy degree of whether $x$ belongs to $A$ or not, with the condition $0 \leq \pi_{A}(x) \leq 1$.

Definition 2 (see [18]). Arithmetic operations on intuitionistic fuzzy numbers

Let both $\alpha=\left(\mu_{A}, v_{A}\right)$ and $\beta=\left(\mu_{B}, v_{B}\right)$ be intuitionistic fuzzy numbers and $\lambda$ be real number. The arithmetic operations on intuitionistic fuzzy numbers are defined as follows:

$$
\begin{aligned}
& \text { (1) } \alpha \oplus \beta=\left(\mu_{A}+\mu_{B}-\mu_{A} \mu_{B}, v_{A} v_{B}\right) \\
& \text { (2) } \lambda \alpha=\left(1-\left(1-\mu_{A}\right)^{\lambda}, v_{A}^{\lambda}\right), \quad \lambda>0 \\
& \text { (3) } \alpha \otimes \beta=\left(\mu_{A} \mu_{B}, v_{A}+v_{B}-v_{A} v_{B}\right) \\
& \text { (4) } \alpha^{\lambda}=\left(\mu_{A}^{\lambda}, 1-\left(1-v_{A}\right)^{\lambda}\right), \quad \lambda>0 \\
& \text { (5) } \frac{\alpha}{\beta}=\left(\min \left(\mu_{A}, \mu_{B}\right), \max \left(v_{A}, v_{B}\right)\right)
\end{aligned}
$$

Definition 3 (see [25]). For intuitionistic fuzzy numbers, the score function of $\alpha$ is defined as

$$
s(\alpha)=k \mu_{\alpha}-k v_{\alpha}+(1-2 k)\left|1-\left(\mu+v_{\alpha}\right)\right|,
$$

where $\mathrm{k}$ reflects the decision attitude of the evaluator and $0<$ $k<1$.
Definition 4 (see [24]). Entropy for intuitionistic fuzzy numbers is as follows.

For intuitionistic fuzzy set $A \in \operatorname{IFS}(x)$, the improved entropy is defined as

$$
\begin{aligned}
E(\mathrm{~A}) & =\frac{1}{\mathrm{n}} \sum_{i=1}^{n}\left[\pi_{A}\left(x_{i}\right)+\frac{\sqrt{2}}{2}\left(1-\pi_{A}\left(x_{i}\right)\right)\right. \\
& \left.-\frac{\sqrt{2}}{2}\left|\mu_{A}\left(x_{i}\right)-v_{A}\left(x_{i}\right)\right|\right]
\end{aligned}
$$

Definition 5 (see [23]). Cross entropy of intuitionistic fuzzy numbers is as follows.

For intuitionistic fuzzy set $A, B \in \operatorname{IFS}(x)$, the cross entropy is defined as

$$
\begin{aligned}
& D(A, B)=\sum_{i=1}^{n}\left[\mu_{A}\left(x_{i}\right) \ln \frac{\mu_{A}\left(x_{i}\right)}{(1 / 2)\left(\mu_{A}\left(x_{i}\right)+\mu_{B}\left(x_{i}\right)\right)}\right. \\
& \left.+v_{A}\left(x_{i}\right) \ln \frac{v_{A}\left(x_{i}\right)}{(1 / 2)\left(v_{A}\left(x_{i}\right)+v_{B}\left(x_{i}\right)\right)}\right] \\
& +\sum_{i=1}^{n}\left[\mu_{B}\left(x_{i}\right) \ln \frac{\mu_{B}\left(x_{i}\right)}{(1 / 2)\left(\mu_{A}\left(x_{i}\right)+\mu_{B}\left(x_{i}\right)\right)}\right. \\
& \left.+v_{B}\left(x_{i}\right) \ln \frac{v_{B}\left(x_{i}\right)}{(1 / 2)\left(v_{A}\left(x_{i}\right)+v_{B}\left(x_{i}\right)\right)}\right]
\end{aligned}
$$

\section{Evaluation Criteria of the Risk of Natural Gas Pipeline Operation Management}

Natural gas is a national strategic resource, and its product characteristic determines its unique risk in the market competition. From the perspective of overall corporate risk, pipeline operation company, like other enterprises, shares the same risks in terms of strategy, law, and human resources. According to $[26,28,29]$, the first level is gotten. Then the evaluation criteria are established based on [11, 26, 28-70], which are shown in Table 1.

3.1. Strategic Risk. Strategic risk of the natural gas pipeline company includes the external macro environment, the industries, the resources, and capabilities in the enterprises [30-32]

3.1.1. Macro Environment. National policies and regulations have influences on the macro environment. To encourage and support the exploration and utilization of natural gas, a series of preferential policies are issued [33]. If these preferential policies change, the company will be influenced significantly. Pipeline companies sell natural gas to downstream industrial and commercial enterprises to make profits [34]. If the domestic economy goes down, the pipeline enterprises will face the decrease of downstream users and the reduction of gas consumption [35]. 
TABLE 1: Evaluation criteria of the risk of natural gas pipeline operation management.

\begin{tabular}{lc}
\hline First level & Second level \\
\hline $\begin{array}{l}\text { Strategic } \\
\text { risk }\left(\mathrm{C}_{1}\right)\end{array}$ & Macro environment $\left(\mathrm{C}_{11}\right)[33-35]$ \\
{$[30-32]$} & Industry environment $\left(\mathrm{C}_{12}\right)[36]$ \\
& Internal resources and \\
capabilities $\left(\mathrm{C}_{13}\right)[37]$ \\
\hline $\begin{array}{l}\text { Market } \\
\text { risk }\left(\mathrm{C}_{2}\right)\end{array}$ & Downstream user $\left(\mathrm{C}_{21}\right)[41]$ \\
{$[38-40]$} & Imbalance between supply and \\
& demand $\left(\mathrm{C}_{22}\right)$ \\
\hline Financial & Price $\left(\mathrm{C}_{23}\right)$ \\
risk $\left(\mathrm{C}_{3}\right)$ & Competition $\left(\mathrm{C}_{24}\right)$ \\
{$[42,43]$} & Debt paying ability $\left(\mathrm{C}_{31}\right)$ \\
& Operating ability $\left(\mathrm{C}_{32}\right)[43-51]$ \\
& Profitability ability $\left(\mathrm{C}_{33}\right)[52]$ \\
Operation & Development ability $\left(\mathrm{C}_{34}\right)[53]$ \\
risk $\left(\mathrm{C}_{4}\right)$ & Human resources $\left(\mathrm{C}_{41}\right)[56-59]$ \\
{$[26,54,55]$} & Material purchase $\left(\mathrm{C}_{42}\right)[60-62]$ \\
\hline & Management system $\left(\mathrm{C}_{43}\right)$ \\
Legal & HSE $\left(\mathrm{C}_{44}\right)[63-65]$ \\
risk $\left(\mathrm{C}_{5}\right)[63]$ & Contract $\left(\mathrm{C}_{51}\right)[66,67]$ \\
& Safety and environmental \\
\hline & protection law $\left(\mathrm{C}_{52}\right)[11,68-70]$ \\
& Labor Law $\left(\mathrm{C}_{53}\right)$ \\
& Operating compliance $\left(\mathrm{C}_{54}\right)$ \\
\hline
\end{tabular}

3.1.2. Industry and Competition Risk. In most countries, the natural gas industry is monopolized [36]. The transportation and sales of natural gas are controlled by the natural gas pipeline company. The alternative pipeline transportation product such as LNG, photovoltaic, and wind energy will break the monopoly. Meanwhile, with the introducing of new competitors, companies will have to reduce margins to participate in competitions.

3.1.3. Internal Resources and Capacity Risk. Strategic planning, implementation, investment decision-making, and operational capability have influence on the internal resources and capacity risk [37]. It is mainly reflected in the unreasonable strategic decision-making, market positioning is not accurate, and the development strategy is not clear. The mismatch between the organizational structure and operation mode and the development strategy will lead to the results that the implementation of the strategy is blocked and the strategic awareness of all staff in the organization is weak, and the planning and execution of the unit cannot be carried out in good accordance with the corporate strategy.

3.2. Market Risk. Market risk refers to the interaction between participants in the market competition, which causes the change of supply and demand in the market, and the uncertainty of this change forms the market risk [38].

The market risk factors of the enterprise can be summed up in four aspects: downstream user risk, unbalanced market supply and demand risk, market price risk, and competition risk $[39,40]$.

3.2.1. Downstream User Risk. Downstream natural gas pipeline users include industrial users, city gas, LNG, and CNG [41]. Downstream user risk is mainly reflected in the gas consumption instability and downstream users stickiness instability. The instability of the gas season will bring unbalanced supply and marketing risks to the upstream exploration and development and midstream pipeline transportation enterprises. In the precondition that the gas has no much more price advantage compared with the oil, coal, and other traditional energy fuel, the cost of equipment replacement and branch line construction will reduce the customer stickiness.

3.2.2. The Imbalance between Supply and Demand Risks. The relationship between supply and demand in the market determines the position of buyers and sellers in the market. For example, in this country with undeveloped industry, the average daily gas consumption is much less than the optimal designed annual gas transmission volume. As a result, the new developed natural gas field is overproduction, forming a buyer's market, and the profit margins of upstream gas fields and midstream processing plants and pipeline enterprises are declining.

3.2.3. Price Risk. The major income resource of the natural gas pipeline companies is pipeline transportation fee. The pricing mechanism of natural gas prices mainly refer to the price of natural gas and natural gas substitute fuels such as oil prices in the international market and then calculate the domestic various types of rates, tax rates, and upstream mining costs and profits to make a comprehensive pricing. With the increase of postproduction costs and operating costs, natural gas prices will be raised accordingly. Gas power plants, ceramics factories, and cement plants are sensitive to price changes. Natural gas prices rise will inevitably lead to the loss of some customers.

3.2.4. Competition Risk. The market competition risks of natural gas pipeline enterprises are mainly reflected in the competition risks of the main alternative energy utilization and competitor risks. The technological development and price changes of alternative energy sources will directly compete with the consumption of natural gas. With the development of technologies such as LNG and LPG, more and more countries export LNG and LPG, and LNG and LPG in the international market will also compete with their own countries' natural gas enterprises. Meanwhile, the other natural gas pipeline will also compete with pipeline companies for customer resources.

3.3. Financial Risk. Corporate financial risk refers to the risk of financial loss caused by the lack of financial rules and regulations, financial operations, and fund management and other noncompliance. The financial risk includes corporate solvency, capital operation ability, corporate profitability, and sustainable development capacity aspects $[42,43]$. 
3.3.1. Corporate Solvency Risk. The liquidity ratio and the quick ratio reflect the ability of the enterprise to repay the current debt in the short term, and they are, respectively, equal to the circulating assets and the ratio of the quick assets to the cash liabilities in a financial period. The ratio of firm's equity reflects the strength and weakness of the stability of the basic financial structure from a single perspective. Interest guarantee rate is used to measure the profitability of the enterprise in the current period to repay interest. The cash flow debt ratio of a company is used to measure the current ability of an enterprise to repay shortterm debts. Long-term asset suitability of enterprises can be used to measure the strength of long-term corporate solvency.

3.3.2. Enterprise Operational Capacity Risk. The analysis of the risk of an enterprise's operational capability can be started by calculating the financial indicators related to the turnover of the enterprise's capital [43-45]. Enterprise accounts receivable [46] turnover rate can be used to measure the flow of corporate accounts receivable. The enterprise inventory turnover rate [47] can be used to measure the turnover rate of the enterprise inventory. Liquidity [48] turnover can be used to measure the profitability of liquid assets in the enterprise. The total asset turnover [49] of an enterprise can be used to measure the rate at which an enterprise invests its assets into output during the business cycle. Nonperforming assets ratio [50] refers to the ratio of nonperforming assets to the total assets of an enterprise in a financial period, which can be used to measure the nonperforming assets of enterprises. The asset loss [51] rate refers to the ratio of the loss on fixed assets to the beginning of the total fixed assets in a financial period, which reflects the loss of fixed assets of the enterprise.

3.3.3. Enterprise Profitability Risk. The analysis of corporate profitability risk can be measured from the following indicators [52]. Operating profit margins measure how much profit a business unit makes. Return on total assets can measure the size of the company's assets operating efficiency. Capital rate of return can reflect the ability of its own capital to obtain net income. The cost-of-business profit margin measures the cost of investing the profit per unit of business.

3.3.4. Enterprise Development Capability Risk. Analysis of enterprise development capability risk can start with the following indicators. Sales growth rate refers to the ratio of sales revenue growth and total sales revenue in the last financial cycle in a financial cycle. It is an important indicator to reflect whether the enterprise is in good condition and the market possession ability is strong or weak [53].

3.4. Operational Risk. Operational risks of natural gas pipeline operation management are classified into human resource risk, material procurement management risk, management system risk, and HSE risk $[26,54,55]$.

3.4.1. Human Resource Risk. Human resources risk is mainly in the following areas [56-58]. The unqualified person may be recruited into the enterprise due to the asymmetric information in the labor market or the unclear job demand analysis of the recruiters. The loss of staff wastage occurs when the employee's contribution to the enterprise has not reached the capital cost invested by the enterprise. Employees neglect their duties, abuse their powers, or violate the enterprise management system to cause financial and reputation losses to the enterprise. Staff injuries cause the enterprise income loss and expenses. Human resource managers' lacking of ability and management ethics causes the managerial corruption [59].

3.4.2. Material Procurement Risk. The material procurement is mainly reflected in three aspects: procurement cost, procurement quality, and procurement time [60]. When it is impossible to purchase materials and spare parts for the daily operation and maintenance of the pipeline at home, the enterprises must invite tenders from abroad for procurement. The procurement cost risk is incurred in international procurement due to price fluctuation, exchange rate fluctuation, and default of bidders. Purchasing quality is influenced by suppliers' noncompliance of supplier quality, incomplete quality supervision, and unqualified quality inspection. The procurement time also has influence on the risk since the production operation is blocked due to the poor procurement, the equipment operation risk increases, and the emergency requirement cannot be satisfied $[61,62]$.

3.4.3. Management System Risk. The risk of management system is mainly manifested in the fact that due to this natural gas pipeline management company just taking over the operation from the construction parties, various management systems in daily operation and management have not been established yet. It will lead to risks such as unscrupulous operation, inefficiency, and poor risk control.

3.4.4. HSE Risk. HSE (Health, Safety, and Environment) [63] risk refers to the risk caused by the HSE management which is not in place, and HSE management system is not established or not completed. HSE budget is insufficient. Safety hazards may not be rectified timely. Many other factors also have influence on the HSE risk such as lacking of staff safety education, fatal accidents, pipeline explosion, leakage accidents, and employee occupational injuries $[64,65]$.

3.5. Legal Risk. Natural gas transmission pipeline has long distance and wide coverage. The relationship between enterprises and local governments is complicated. There are contract risks, legal risks of safety and environmental protection, labor law risks, and operation compliance risks in operation of natural gas pipeline [63].

3.5.1. Contract Risk. The contract risk is reflected in the signing and fulfillment of the contract [66]. The natural gas pipeline company is in the middle position in the oil and gas industry chain and plays a role of transformation. Therefore, many contracts and market transactions exist between pipeline companies and upstream gas fields and downstream users. Once the contract is formulated and 
implemented, the enterprise will face the risk of breach of contract [67].

3.5.2. Safety and Environmental Legal Risks. Natural gas pipeline transportation industry belongs to the high-risk industry $[11,68]$. The massive natural gas leakage will cause some pollution to the environment $[69,70]$. The high-pressure natural gas pipeline passes through the villages and cities along the pipeline route. Once the leakage, explosion, and fire accidents occur, the consequences will be disastrous. Therefore, the pipeline safety management is under strict supervision of local authorities.

3.5.3. Labor Law Risks. The operation of pipelines employs many workers and has diversified employment patterns. There are protection mechanisms for employees' rights. Especially with the improvement of the education level of the staff, the awareness of rights protection is very strong.

3.5.4. Operation Compliance Risk. Operation compliance risks are mainly reflected in the business-related licenses or qualifications that have not been obtained for a business. There is no synchronization with the latest laws, regulations, or industry standards promulgated by the state. Company may be charged with illegal business operations and so on.

\section{Method to Deal with the Linguistic Evaluation Information in Intuitionistic Fuzzy Linguistic Environment}

Let $E=\left\{e_{1}, e_{2}, \ldots, e_{s}\right\}$ be the set of evaluators, $m_{i}$ be the alternative, and $C=C_{1} \cup C_{2} \cup \cdots \cup C_{l}=\left\{c_{1}, c_{2}, \ldots, c_{n}\right\}$ be the criteria. The weight vector of the evaluator obtained by subjective weighting method is $\lambda=\left(\lambda_{1}, \lambda_{2}, \ldots, \lambda_{s}\right)^{T}$, with the condition $0 \leq \lambda_{k} \leq 1, k=1,2, \ldots, s$ and $\sum_{k=1}^{s} \lambda_{k}=1$.

Evaluators $e_{k}$ evaluate the alternative $m_{i}$ according to the criterion $c_{j}$ to obtain the intuitionistic fuzzy decision matrix $R^{k}=\left(\alpha_{i j}^{k}\right)_{n \times m}$ under the attribute of the alternative, in which $\alpha_{i j}^{k}=\left(\mu_{i j}^{k}, v_{i j}^{k}\right), 0 \leq \mu_{i j}^{k} \leq 1,0 \leq v_{i j}^{k} \leq 1,0 \leq \mu_{i j}^{k}+v_{i j}^{k} \leq$ $1, \pi_{i j}^{k}=1-\mu_{i j}^{k}-v_{i j}^{k}$, and $\mu_{i j}^{k}, v_{i j}^{k}, \pi_{i j}^{k}$ respectively, expresses the satisfaction, dissatisfaction, and hesitancy degree of evaluator $e_{k}$ under the attributes $c_{j}$ of the alternative $m_{i}$.

The higher the consistency of experts' opinion on evaluation of criteria weight, the greater the weight of experts in weight evaluation [71]. More experts agree on the criteria weight and risk assessment; the more understanding of the criteria and the enterprise risk, the greater the weight of the experts in the risk assessment. In the following, based on the work $[23-25,71,72]$, the linguistic evaluation information is dealt with by the following steps.

Step 1. Assume that the rating of alternative $\mathrm{m}_{\mathrm{i}}$ with respect to criterion $c_{j}$ given by the evaluators $e_{k}$ can be expressed in IFS $r_{i j}^{(k)}=\left(\mu_{i j}^{(k)}, v_{i j}^{(k)}, \pi_{i j}^{(k)}\right)$; the rating of importance of criterion $c_{j}$ given by the evaluatorse $e_{k}$ can be expressed in IFS $w_{j}^{(k)}=\left(\mu_{j}^{(k)}, v_{j}^{(k)}, \pi_{j}^{(k)}\right)$. Therefore, the corresponding intuitionistic fuzzy decision matrices $R^{(k)}$ and $W^{(k)}$ can be expressed in matrix form concisely as follows:

$$
\begin{aligned}
& R^{(k)}=\left(r_{i j}^{(k)}\right)_{n \times m}=\left[\begin{array}{cccc}
r_{11}^{(k)} & r_{12}^{(k)} & \cdots & r_{1 n}^{(k)} \\
r_{21}^{(k)} & r_{22}^{(k)} & \cdots & r_{2 n}^{(k)} \\
\vdots & \vdots & \vdots & \vdots \\
r_{m 1}^{(k)} & r_{m 2}^{(k)} & \cdots & r_{m n}^{(k)}
\end{array}\right], \\
& W^{(k)}=\left(w_{1}^{(k)}, w_{2}^{(k)}, \ldots, w_{n}^{(k)}\right)
\end{aligned}
$$

where $r_{i j}^{(k)}=\left(\mu_{i j}^{(k)}, v_{i j}^{(k)}, \pi_{i j}^{(k)}\right), w_{j}^{(k)}=\left(\mu_{j}^{(k)}, v_{j}^{(k)}, \pi_{j}^{(k)}\right)$

Step 2. Construct the initial aggregated intuitionistic fuzzy decision matrix separately.

Step 2.1

According to (3), construct the aggregated intuitionistic fuzzy decision matrix $P=\left(\delta_{1}, \delta_{2}, \ldots, \delta_{n}\right)$ based on the importance of criteria by

$$
\begin{aligned}
& \delta_{j}=\bigoplus_{k=1}^{s} w_{j}^{(k)} \lambda_{k}=\left(\mu_{j}, v_{j}\right), \\
& \mu_{i}=1-\prod_{k=1}^{s}\left(1-\mu_{j}^{(k)}\right)^{w_{j}^{(k)}}, \\
& v_{k_{i}}=\prod_{k=1}^{s}\left(v_{j}^{(k)}\right)^{w_{j}^{(k)}}
\end{aligned}
$$

Step 2.2

According to (3), construct the initial aggregated intuitionistic fuzzy decision matrix $Q=\left(\alpha_{i j}\right)_{n \times m}$ based on the rating of alternative by

$$
\begin{aligned}
\alpha_{i j} & =\bigoplus_{K=1}^{s} r_{i j}^{k} \lambda_{k}=\left(\mu_{i j}, v_{i j}\right) \\
& =\left(1-\prod_{k=1}^{s}\left(1-\mu_{i j}^{k}\right)^{\lambda_{k}}, \prod_{k=1}^{s}\left(v_{i j}^{k}\right)^{\lambda_{k}}\right)
\end{aligned}
$$

Step 3. Obtain the entropy weight.

Step 3.1

Based on (8), obtain the entropy weight $H_{c}\left(e_{k}\right)$ of evaluators $e_{k}$ on the evaluation of criteria by

$$
\begin{aligned}
& E_{c}^{k}=\frac{1}{\mathrm{n}} \sum_{i=1}^{n}\left[\pi_{j}^{(k)}+\frac{\sqrt{2}}{2}\left(1-\pi_{j}^{(k)}\right)-\frac{\sqrt{2}}{2}\left|\mu_{j}^{(k)}-v_{j}^{(k)}\right|\right] \\
& H_{c}\left(e_{k}\right)=\frac{\left(1-E_{c}^{k}\right)}{\left(s-\sum_{k=1}^{s} E_{c}^{k}\right)} .
\end{aligned}
$$


Step 3.2

Based on (8), obtain the entropy weight $H_{m_{i}}\left(e_{k}\right)$ of evaluators on the evaluation of alternative $m_{i}$ by

$$
\begin{aligned}
& E_{i}^{k}=\frac{1}{\mathrm{n}} \sum_{i=1}^{n}\left[\pi_{i j}^{(k)}+\frac{\sqrt{2}}{2}\left(1-\pi_{i j}^{(k)}\right)-\frac{\sqrt{2}}{2}\left|\mu_{i j}^{(k)}-v_{i j}^{k}\right|\right] \\
& H_{m_{i}}\left(e_{k}\right)=\frac{\left(1-E_{i}^{k}\right)}{\left(s-\sum_{k=1}^{s} E_{i}^{k}\right)} .
\end{aligned}
$$

Step 4. Calculate the cross entropy weight.

\section{Step 4.1}

Based on (9), Calculate the cross entropy weight $C_{c}\left(e_{k}\right)$ of evaluator $e_{k}$ on the evaluation of criteria using

$$
\begin{aligned}
& \boldsymbol{D}_{c}\left(\boldsymbol{Y}_{c}^{k}, \boldsymbol{X}_{c}\right)=\sum_{j=1}^{n}\left[\mu_{j}^{(k)} \ln \frac{\mu_{j}^{(k)}}{(\mathbf{1} / \mathbf{2})\left(\mu_{j}^{(k)}+\mu_{j}\right)}\right. \\
& \left.+v_{i j}^{(k)} \ln \frac{v_{j}^{(k)}}{(\mathbf{1} / \mathbf{2})\left(v_{j}^{(k)}+v_{j}\right)}\right] \\
& +\sum_{j=1}^{n}\left[\mu_{j} \ln \frac{\mu_{j}}{(\mathbf{1} / \mathbf{2})\left(\mu_{j}^{(k)}+\mu_{j}\right)}\right. \\
& \left.+v_{j} \ln \frac{v_{j}}{(\mathbf{1} / \mathbf{2})\left(v_{j}^{(k)}+v_{j}\right)}\right] \\
& C_{c}\left(e_{k}\right)=\frac{1 / \boldsymbol{D}_{c}\left(\boldsymbol{Y}_{c}^{k}, \boldsymbol{X}_{c}\right)}{\sum_{\boldsymbol{k}=\mathbf{1}}^{\boldsymbol{s}}\left(1 / \boldsymbol{D}_{c}\left(\boldsymbol{Y}_{c}^{k}, \boldsymbol{X}_{c}\right)\right)}
\end{aligned}
$$

Step 4.2

Based on (9), calculate the cross entropy weight $C_{m_{i}}\left(e_{k}\right)$ on the evaluation of alternative $m_{i}$ using

$$
\begin{gathered}
\boldsymbol{D}_{m_{i}}\left(\boldsymbol{Y}_{m_{i}}^{k}, \boldsymbol{X}_{m_{i}}\right)=\sum_{j=\mathbf{1}}^{n}\left[\mu_{i j}^{(k)} \ln \frac{\mu_{i j}^{(k)}}{(\mathbf{1} / \mathbf{2})\left(\mu_{i j}^{(k)}+\mu_{i j}\right)}\right. \\
\left.+v_{i j}^{(k)} \ln \frac{v_{i j}^{(k)}}{(\mathbf{1} / \mathbf{2})\left(v_{i j}^{(k)}+v_{i j}\right)}\right] \\
+\sum_{j=\mathbf{1}}^{n}\left[\mu_{i j} \ln \frac{\mu_{i j}}{(\mathbf{1} / \mathbf{2})\left(\mu_{i j}^{(k)}+\mu_{i j}\right)}\right. \\
\left.+v_{i j} \ln \frac{v_{i j}}{(\mathbf{1} / \mathbf{2})\left(v_{i j}^{(k)}+v_{i j}\right)}\right], \\
C_{m_{i}}\left(e_{k}\right)=\frac{1 / \boldsymbol{D}_{m_{i}}\left(\boldsymbol{Y}_{m_{i}}^{k}, \boldsymbol{X}_{m_{i}}\right)}{\sum_{\boldsymbol{k}=\mathbf{1}}^{\boldsymbol{s}}\left(1 / \boldsymbol{D}_{m_{i}}\left(\boldsymbol{Y}_{m_{i}}^{k}, \boldsymbol{X}_{m_{i}}\right)\right)}
\end{gathered}
$$

Step 5. Attain the corresponding final weight based on the cross entropy weights and entropy weights of evaluator $e_{k}$.
Step 5.1

According to the cross entropy weights and entropy weights of evaluator $e_{k}$ on the evaluation of importance of criteria, we can get the corresponding final weight $\eta_{c}^{k}$ by

$$
\eta_{c}^{k}=\alpha C_{c}\left(e_{k}\right)+(1-\alpha) H_{c}\left(e_{k}\right) \text {. }
$$

where $0 \leq \alpha \leq 1$.

Step 5.2

According to the cross entropy weights and entropy weights of evaluators on the evaluation of alternative $m_{i}$, we can get the corresponding final weight $\eta_{i}^{K}$ by

$$
\eta_{i}^{k}=\alpha C_{m_{i}}\left(e_{k}\right)+(1-\alpha) H_{m_{i}}\left(e_{k}\right)
$$

where $0 \leq \alpha \leq 1$

Step 5.3

Based on $\eta_{c}^{k}$ and $\eta_{i}^{k}$, calculate the corresponding final weight $\eta^{k}$, which comprehensively considers the consistency of indicator evaluation and the indicator scores of evaluators by

$$
\eta^{k}=\theta \eta_{c}^{k}+(1-\theta) \eta_{i}^{k}
$$

where $0 \leq \theta \leq 1$.

Step 6. Calculate the integrated evaluation result matrix.

Step 6.1

Integrating the weight based on the rating of criteria of evaluators, based on (4), the integrated evaluation result matrix $B_{c}=\left(\beta_{1}, \beta_{2}, \ldots, \beta_{n}\right)$ of criteria can be obtained by

$$
\beta_{j}=\sum_{k=1}^{s} w_{j}^{(k)} \eta_{c}^{k}=\left(\rho_{j}, \sigma_{j}\right) .
$$

Step 6.2

Integrating the weight based on both the rating of alternatives and the rating of criteria of evaluators, based on (4), the integrated evaluation result matrix $B_{m_{i}}=\left(\beta_{i j}\right)_{n \times m}$ of alternative $m_{i}$ is derived by

$$
\beta_{i j}=\sum_{k=1}^{s} \alpha_{i j}^{(k)} \eta^{k}=\left(\rho_{i j}, \sigma_{i j}\right) .
$$

Step 7. Determine the final evaluation results. Based on (2)-(6), the weighted evaluation value of the alternative $m_{i}$ with respect to the parent criteria $C_{l}$ can be derived by

$$
\begin{aligned}
\xi_{i l} & =\frac{\sum_{c_{j} \in C_{l}} \beta_{i j} \otimes \beta_{j}}{\sum_{c_{j} \in C_{l}} \beta_{j}}=\frac{\sum_{c_{j} \in C_{l}}\left(\rho_{i j}, \sigma_{i j}\right) \otimes\left(\rho_{j}, \sigma_{j}\right)}{\sum_{c_{j} \in C_{l}}\left(\rho_{j}, \sigma_{j}\right)} \\
& =\left(\rho_{i l}, \sigma_{i l}\right),
\end{aligned}
$$

Step 8. In the condition that the weighted rating of the alternative with the parent criteria needs to be compared, based on (7), the score function can be used as

$$
s\left(\xi_{i l}\right)=k \rho_{i l}-k \sigma_{i l}+(1-2 k)\left|1-\left(\rho_{i l}+\sigma_{i l}\right)\right|
$$


TABLE 2: Linguistic term sets.

\begin{tabular}{lcc}
\hline $\begin{array}{l}\text { Linguistic terms for } \\
\text { weight of criteria }\end{array}$ & $\begin{array}{c}\text { Linguistic terms } \\
\text { for risk level }\end{array}$ & IFNs \\
\hline Very importance(VI) & Very high(VH) & $(0.90,0.05,0.05)$ \\
Importance(I) & $\operatorname{High}(\mathrm{H})$ & $(0.75,0.20,0.05)$ \\
Medium(F) & $\operatorname{Medium}(\mathrm{F})$ & $(0.50,0.40,0.10)$ \\
Unimportance(U) & $\operatorname{Low}(\mathrm{L})$ & $(0.25,0.60,0.15)$ \\
Very & Very low(VL) & $(0.10,0.80,0.10)$ \\
unimportance(VU) & & \\
\hline
\end{tabular}

\section{Illustrate Example}

In order to control the risks of X Gas Pipeline Company, the proposed approach is used to evaluate the risks. Seven people are invited to evaluate the risk of company and the weight of criteria using the linguistic terms in Table 2.

\subsection{Deriving the Evaluation Results}

Step 1. Construct the individual intuitionistic fuzzy decision matrix.

Using Table 2, the initial ratings are converted into the intuitionistic fuzzy forms in Tables 3 and 4.

Step 2. Construct the initial aggregated intuitionistic fuzzy decision matrix separately.

Step 2.1

Weights of the experts are equal; then with (11)-(12) the matrix can be derived, as is in the fourth column of Table 5 .

Step 2.2

Weights of the experts are equal; with (13), the initial aggregated intuitionistic fuzzy decision matrix of risk level of the company can be derived, as in the second column of Table 5.

Step 3. Obtain the entropy weight.

Step 3.1

The entropy weights of evaluators based on the evaluation of the criteria can be calculated with (14)-(15).

$$
\begin{aligned}
& H_{c}\left(e_{1}\right)=0.19, \\
& H_{c}\left(e_{2}\right)=0.19, \\
& H_{c}\left(e_{3}\right)=0.11, \\
& H_{c}\left(e_{4}\right)=0.12, \\
& H_{c}\left(e_{5}\right)=0.12, \\
& H_{c}\left(e_{6}\right)=0.13, \\
& H_{c}\left(e_{7}\right)=0.12 .
\end{aligned}
$$

Step 3.2

The entropy weights of evaluators based on the evaluation of the company can be calculated with (16)-(17).

$$
H_{x}\left(e_{1}\right)=0.13 \text {, }
$$

$$
\begin{aligned}
& H_{x}\left(e_{2}\right)=0.14, \\
& H_{x}\left(e_{3}\right)=0.15, \\
& H_{x}\left(e_{4}\right)=0.17, \\
& H_{x}\left(e_{5}\right)=0.14, \\
& H_{x}\left(e_{6}\right)=0.13, \\
& H_{x}\left(e_{7}\right)=0.14 .
\end{aligned}
$$

Step 4. Calculate the cross entropy weight.

Step 4.1

With (18)-(19), the cross entropy weight of evaluators based on evaluation of the criteria can be derived.

$$
\begin{aligned}
& C_{c}\left(e_{1}\right)=0.14, \\
& C_{c}\left(e_{2}\right)=0.10, \\
& C_{c}\left(e_{3}\right)=0.19, \\
& C_{c}\left(e_{4}\right)=0.12, \\
& C_{c}\left(e_{5}\right)=0.16, \\
& C_{c}\left(e_{6}\right)=0.13, \\
& C_{c}\left(e_{7}\right)=0.16 .
\end{aligned}
$$

Step 4.2

With (20)-(21), the cross entropy weight of evaluators based on evaluation of the company can be derived.

$$
\begin{aligned}
& C_{x}\left(e_{1}\right)=0.14, \\
& C_{x}\left(e_{2}\right)=0.19, \\
& C_{x}\left(e_{3}\right)=0.14, \\
& C_{x}\left(e_{4}\right)=0.10, \\
& C_{x}\left(e_{5}\right)=0.15, \\
& C_{x}\left(e_{6}\right)=0.13, \\
& C_{x}\left(e_{7}\right)=0.15 .
\end{aligned}
$$

Step 5. Attain the corresponding final weight based on the cross entropy weights and entropy weights.

Step 5.1

Let $\alpha=0.6, \beta=0.4$; then using (22), the final weight of evaluators based on the evaluation of criteria can be gotten.

$$
\begin{aligned}
& \eta_{c}^{1}=0.16, \\
& \eta_{c}^{2}=0.14, \\
& \eta_{c}^{3}=0.16, \\
& \eta_{c}^{4}=0.12, \\
& \eta_{c}^{5}=0.15,
\end{aligned}
$$




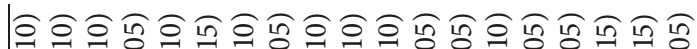

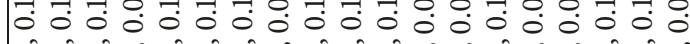

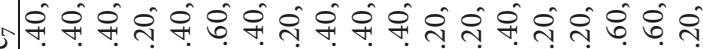

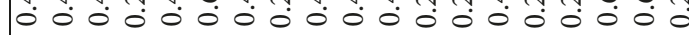

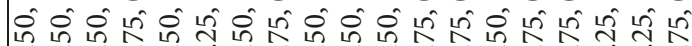

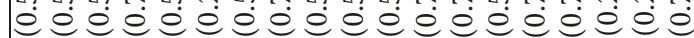

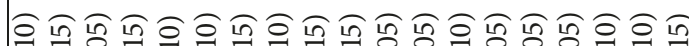

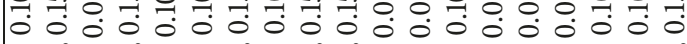

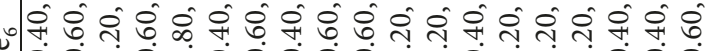

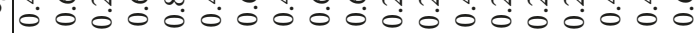

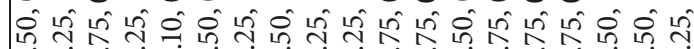

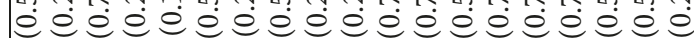

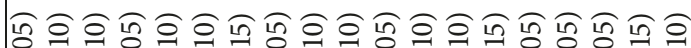

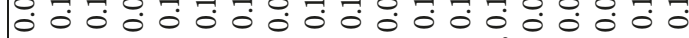
m की की

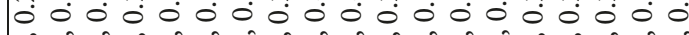

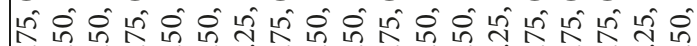

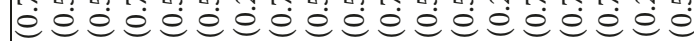

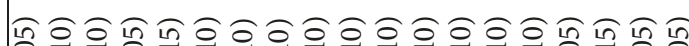

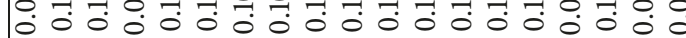

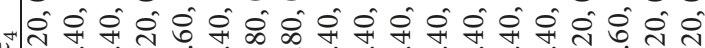

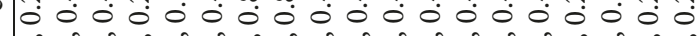

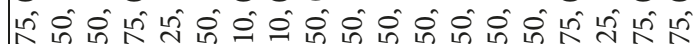

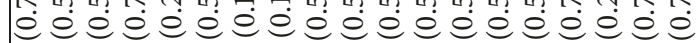

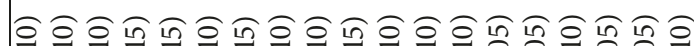

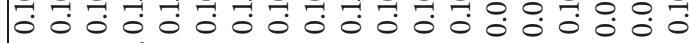

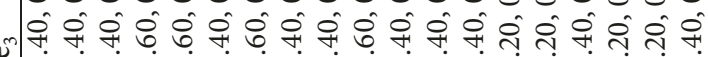

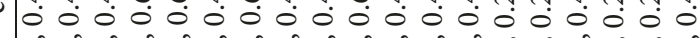

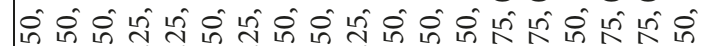

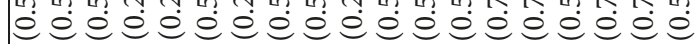

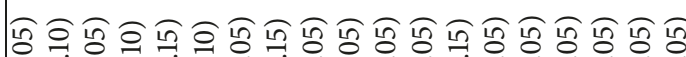

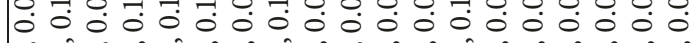

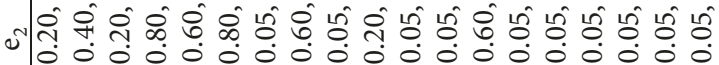

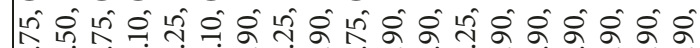

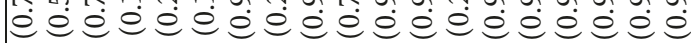

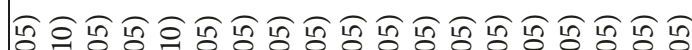
0.00 .0000000000000$.

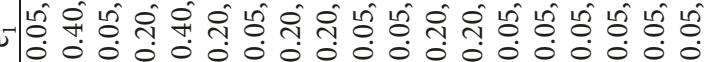
ดी ถी

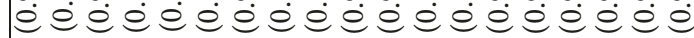




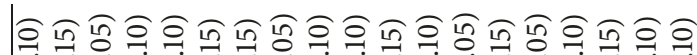
- 0 0 0 0 0 0 0 0 0 0 0 0 0 0 0 0 0.

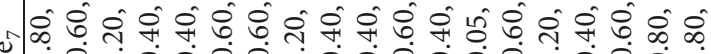

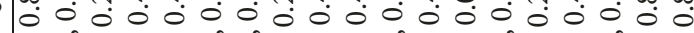

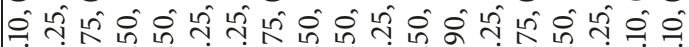

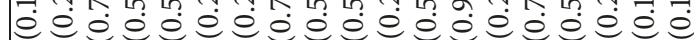

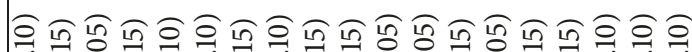

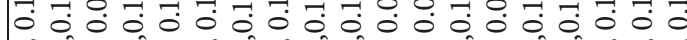

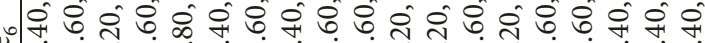

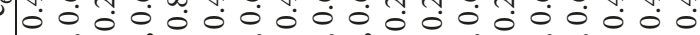

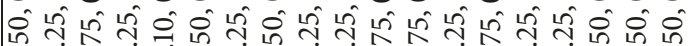

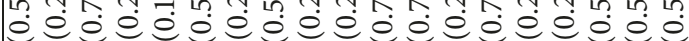

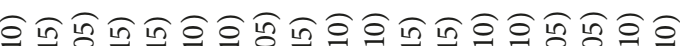

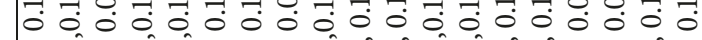

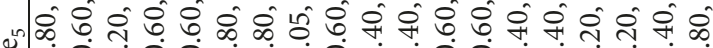

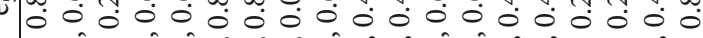

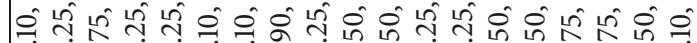
é巳仓

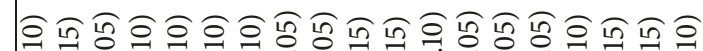

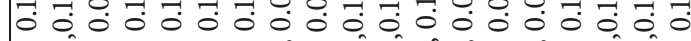
म

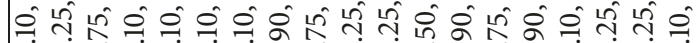

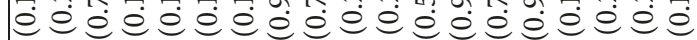

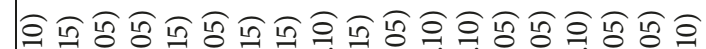

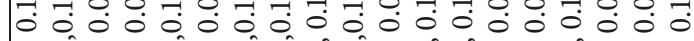

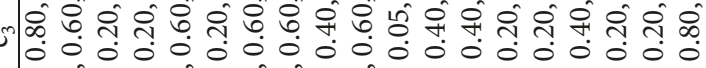

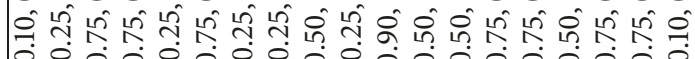

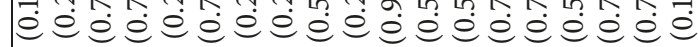

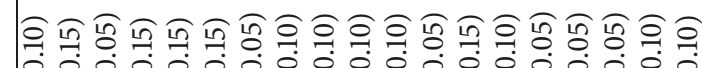

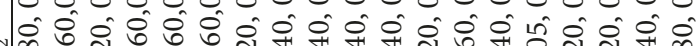

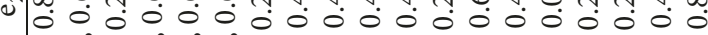

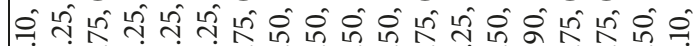
é巳

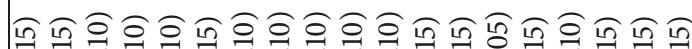

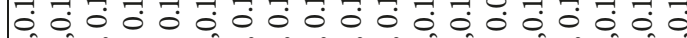

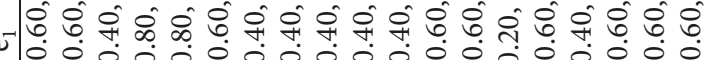

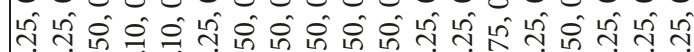

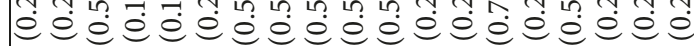

जิ 
TABLE 5: Intuitionistic fuzzy decision matrixes.

\begin{tabular}{|c|c|c|c|c|}
\hline Criteria & $\begin{array}{l}\text { Initial } \\
\text { aggregated risk } \\
\text { level of the } \\
\text { company }\end{array}$ & $\begin{array}{l}\text { Ratings of the } \\
\text { company with } \\
\text { weight of } \\
\text { experts }\end{array}$ & $\begin{array}{c}\text { Initial } \\
\text { aggregated } \\
\text { weight of } \\
\text { criteria }\end{array}$ & $\begin{array}{c}\text { Weighted } \\
\text { ratings of } \\
\text { criteria }\end{array}$ \\
\hline $\mathrm{C}_{11}$ & $(0.19,0.70)$ & $(0.19,0.70)$ & $(0.70,0.22)$ & $(0.70,0.22)$ \\
\hline $\mathrm{C}_{12}$ & $(0.25,0.60)$ & $(0.25,0.60)$ & $(0.47,0.42)$ & $(0.47,0.42)$ \\
\hline $\mathrm{C}_{13}$ & $(0.72,0.22)$ & $(0.72,0.22)$ & $(0.67,0.24)$ & $(0.68,0.24)$ \\
\hline $\mathrm{C}_{21}$ & $(0.36,0.53)$ & $(0.37,0.52)$ & $(0.59,0.33)$ & $(0.59,0.33)$ \\
\hline $\mathrm{C}_{22}$ & $(0.24,0.64)$ & $(0.24,0.64)$ & $(0.35,0.53)$ & $(0.36,0.52)$ \\
\hline $\mathrm{C}_{23}$ & $(0.36,0.53)$ & $(0.37,0.52)$ & $(0.48,0.42)$ & $(0.49,0.42)$ \\
\hline $\mathrm{C}_{24}$ & $(0.36,0.53)$ & $(0.37,0.52)$ & $(0.59,0.29)$ & $(0.61,0.28)$ \\
\hline $\mathrm{C}_{31}$ & $(0.70,0.21)$ & $(0.69,0.22)$ & $(0.57,0.35)$ & $(0.59,0.33)$ \\
\hline $\mathrm{C}_{32}$ & $(0.49,0.41)$ & $(0.49,0.41)$ & $(0.62,0.29)$ & $(0.62,0.28)$ \\
\hline $\mathrm{C}_{33}$ & $(0.41,0.48)$ & $(0.41,0.47)$ & $(0.60,0.30)$ & $(0.61,0.29)$ \\
\hline $\mathrm{C}_{34}$ & $(0.60,0.30)$ & $(0.60,0.30)$ & $(0.74,0.18)$ & $(0.75,0.18)$ \\
\hline $\mathrm{C}_{41}$ & $(0.54,0.37)$ & $(0.54,0.37)$ & $(0.70,0.22)$ & $(0.70,0.22)$ \\
\hline $\mathrm{C}_{42}$ & $(0.60,0.28)$ & $(0.59,0.30)$ & $(0.57,0.35)$ & $(0.57,0.34)$ \\
\hline $\mathrm{C}_{43}$ & $(0.64,0.20)$ & $(0.64,0.30)$ & $(0.73,0.19)$ & $(0.73,0.19)$ \\
\hline $\mathrm{C}_{44}$ & $(0.71,0.38)$ & $(0.71,0.20)$ & $(0.79,0.15)$ & $(0.79,0.14)$ \\
\hline $\mathrm{C}_{51}$ & $(0.53,0.35)$ & $(0.54,0.37)$ & $(0.79,0.15)$ & $(0.79,0.15)$ \\
\hline $\mathrm{C}_{52}$ & $(0.56,0.35)$ & $(0.57,0.35)$ & $(0.71,0.20)$ & $(0.72,0.19)$ \\
\hline $\mathrm{C}_{53}$ & $(0.45,0.50)$ & $(0.45,0.45)$ & $(0.71,0.20)$ & $(0.71,0.20)$ \\
\hline $\mathrm{C}_{54}$ & $(0.19,0.70)$ & $(0.19,0.70)$ & $(0.73,0.19)$ & $(0.73,0.19)$ \\
\hline
\end{tabular}

$$
\begin{aligned}
& \eta_{c}^{6}=0.13 \\
& \eta_{c}^{7}=0.15 .
\end{aligned}
$$

Step 5.2

Let $\alpha=0.6, \beta=0.4$; then using (23), the final weight of evaluators based on the evaluation of evaluation of the company can be gotten.

$$
\begin{aligned}
& \eta_{x}^{1}=0.13, \\
& \eta_{x}^{2}=0.17, \\
& \eta_{x}^{3}=0.14, \\
& \eta_{x}^{4}=0.13, \\
& \eta_{x}^{5}=0.15 \\
& \eta_{x}^{6}=0.13 \\
& \eta_{x}^{7}=0.14
\end{aligned}
$$

\section{Step 5.3}

Let $\theta=0.5$; based on $\eta_{c}^{k}$ and $\eta_{i}^{k}$, calculate the corresponding final weight $\eta^{k}$, which comprehensively considers the consistency of evaluation indicators of evaluators and the indicator scores by (24).

$$
\eta^{1}=0.15
$$

$$
\begin{aligned}
& \eta^{2}=0.15 \\
& \eta^{3}=0.15 \\
& \eta^{4}=0.12, \\
& \eta^{5}=0.15 \\
& \eta^{6}=0.13 \\
& \eta^{7}=0.14
\end{aligned}
$$

Step 6. Calculate the integrated evaluation result matrix.

Step 6.1

The weighted evaluation result of the criteria can be derived with (25). The results are shown in the fifth column of Table 5 .

Step 6.2

The ratings of risk level of the company integrated with weight of experts can be derived with (26). The results are shown in the third column of Table 5.

Step 7 and 8

Let $k=0.5$. By using (27)-(28), the weighted evaluation value of the company with respect to the parent criteria and the corresponding score value can be derived, which are shown in Table 6. 
TABLE 6: Weighted evaluation value of the company in the first level.

\begin{tabular}{lccc}
\hline Criteria & Weighted evaluation value & Score value & Rank \\
\hline Strategic risk & $(0.61,0.24)$ & 0.19 & Fourth \\
Market risk & $(0.55,0.26)$ & 0.14 & Fifth \\
Financial risk & $(0.83,0.07)$ & 0.38 & Second \\
Operation risk & $(0.90,0.04)$ & 0.43 & First \\
Legal risk & $(0.80,0.09)$ & 0.35 & Third \\
\hline
\end{tabular}

Overall, the risk of gas pipeline operation management is not high. Among the risks, the operation risk is higher than other risks and market risk is lowest.

\section{Conclusions}

As the risks control is important for safeguarding the operation of natural gas pipelines. In the paper, the evaluation of the risk of natural gas pipeline operation management is studied. Firstly, the comprehensive evaluation criteria for the risk of natural gas pipeline operation management are constructed. It is constructed from the strategic risk, market risk, financial risk, operation risk, and legal risk aspects. Since the ratings are given in linguistic terms. In order to deal with these ratings, the intuitionistic fuzzy model is used to represent the linguistic terms. The illustrated example shows the proposed approach is feasible.

\section{Data Availability}

The data used to support the findings of this study are available from the corresponding author upon request.

\section{Conflicts of Interest}

The authors declare that they have no conflicts of interest.

\section{Acknowledgments}

This work was supported by the National Natural Science Foundation of China under Grants 71571191 and 91646122, the Humanity and Social Science Youth Foundation of Ministry of Education in China (Project nos. 15YJCZH081 and 13YJC790112), the Science Foundation of China University of Petroleum, Beijing (no. 2462015YQ0722), and Beijing Natural Science Foundation (no. 9162003).

\section{References}

[1] A. Correljé and C. van der Linde, "Energy supply security and geopolitics: A European perspective," Energy Policy, vol. 34, no. 5, pp. 532-543, 2006.

[2] W. Z. Khan, M. Y. Aalsalem, W. Gharibi, and Q. Arshad, "Oil and gas monitoring using wireless sensor networks: requirements, issues and challenges," in Proceedings of the 2016 International Conference on Radar, Antenna, Microwave, Electronics, and Telecommunications, ICRAMET 2016, pp. 31-35, Jakarta, Indonesia, October 2016.
[3] P. K. Dey, "Analytic hierarchy process analyzes risk of operating cross-country petroleum pipelines in india," Natural Hazards Review, vol. 4, no. 4, pp. 213-221, 2003.

[4] P. K. Dey, "Managing project risk using combined analytic hierarchy process and risk map," Applied Soft Computing, vol. 10, no. 4, pp. 990-1000, 2010.

[5] S. Karimi, R. Sam, J. Balist, and S. M. Bigdeli, "Pipeline risk assessment by using hazard risk assessment, (HAZOP) Method (Case study: Gas transmission Pipeline Of Savadkooh, Iran)," Environmental Science: An Indian Journal, vol. 12, no. 3, 2016.

[6] Z. Zhou, J. Gong, A. Roda, and K. Farrag, "Multiresolution change analysis framework for postdisaster assessment of natural gas pipeline risk," Transportation Research Record, vol. 2595, pp. 29-39, 2016.

[7] M. Bai, Y. Du, Y. Chen, Y. Xing, and P. Zhao, "Risk assessment of long gas and oil pipeline projects inducing landslide disasters during construction," Journal of Performance of Constructed Facilities, vol. 31, no. 5, Article ID 04017063, 2017.

[8] J. Soszynska, "Reliability and risk evaluation of a port oil pipeline transportation system in variable operation conditions," International Journal of Pressure Vessels and Piping, vol. 87, no. 2-3, pp. 81-87, 2010.

[9] Z. Y. Han and W. G. Weng, "Comparison study on qualitative and quantitative risk assessment methods for urban natural gas pipeline network," Journal of Hazardous Materials, vol. 189, no. 1-2, pp. 509-518, 2011.

[10] A. Jamshidi, A. Yazdani-Chamzini, S. H. Yakhchali, and S. Khaleghi, "Developing a new fuzzy inference system for pipeline risk assessment," Journal of Loss Prevention in the Process Industries, vol. 26, no. 1, pp. 197-208, 2013.

[11] Y.-D. Jo and J. A. Bum, "A method of quantitative risk assessment for transmission pipeline carrying natural gas," Journal of Hazardous Materials, vol. 123, no. 1-3, pp. 1-12, 2005.

[12] H. S. Tooranloo and A. S. Ayatollah, "A model for failure mode and effects analysis based on intuitionistic fuzzy approach," Applied Soft Computing, vol. 49, pp. 238-247, 2016.

[13] M. Li and C. Wu, "A distance model of intuitionistic fuzzy cross entropy to solve preference problem on alternatives," Mathematical Problems in Engineering, vol. 2016, Article ID 8324124, 9 pages, 2016.

[14] F. Wang, S. Zeng, and C. Zhang, "A method based on intuitionistic fuzzy dependent aggregation operators for supplier selection," Mathematical Problems in Engineering, vol. 2013, Article ID 481202, 9 pages, 2013.

[15] C. Chen, "Extensions of the TOPSIS for group decision-making under fuzzy environment," Fuzzy Sets and Systems, vol. 114, no. 1, pp. 1-9, 2000.

[16] W.-F. Dai, Q.-Y. Zhong, and C.-Z. Qi, "Multistage multiattribute group decision-making method based on triangular fuzzy MULTIMOORA," Mathematical Problems in Engineering, vol. 2016, Article ID 1687068, 8 pages, 2016. 
[17] K. T. Atanassov, "Intuitionistic fuzzy sets," Fuzzy Sets and Systems, vol. 20, no. 1, pp. 87-96, 1986.

[18] Z. Xu, "Intuitionistic fuzzy aggregation operators," IEEE Transactions on Fuzzy Systems, vol. 15, no. 6, pp. 1179-1187, 2007.

[19] C. Kahraman, S. Cevik Onar, S. Cebi, and B. Oztaysi, "Extension of information axiom from ordinary to intuitionistic fuzzy sets: An application to search algorithm selection," Computers \& Industrial Engineering, vol. 105, pp. 348-361, 2017.

[20] Y. Zhang, Y. Zhang, Y. Li, S. Liu, and J. Yang, "A study of rural logistics center location based on intuitionistic fuzzy TOPSIS," Mathematical Problems in Engineering, vol. 2017, Article ID 2323057, 7 pages, 2017.

[21] J. Guo, "Hybrid multicriteria group decision making method for information system project selection based on intuitionistic fuzzy theory," Mathematical Problems in Engineering, vol. 2013, Article ID 859537, 12 pages, 2013.

[22] K. Govindan, R. Khodaverdi, and A. Vafadarnikjoo, "Intuitionistic fuzzy based DEMATEL method for developing green practices and performances in a green supply chain," Expert Systems with Applications, vol. 42, no. 20, pp. 7207-7220, 2015.

[23] I. K. Vlachos and G. D. Sergiadis, "Intuitionistic fuzzy information-applications to pattern recognition," Pattern Recognition Letters, vol. 28, no. 2, pp. 197-206, 2007.

[24] L. Z. Song, G. Peng, and W. Y. Yang, "Extension factor for surfaces with maximum in region experiments," Computer Engineering and Applications, vol. 45, no. 7, pp. 187-189, 2009 (Chinese).

[25] C. Wang, D. Yao, J. Mao, and L. Sun, "Intuitionistic fuzzy multiple attributes decision making method based on entropy and correlation coefficient," Journal of Computer Applications, vol. 32, no. 11, pp. 3002-3004, 2012.

[26] Z. Yanjiao, Research of the internal control risk classification management based on sinopec pipeline storage and transportation company [M.S. thesis], Yangtze University, Hubei, China, 2015.

[27] T. Wei, "Construction of legal risk and prevention and control mechanism for long-distance natural gas pipeline enterprises," Oriental Enterprise Culture, vol. 10, article 165, 2014.

[28] S. Wei, Research oil evaluation of risk management in Liaohe Petroleum [M.S. thesis], Dalian University of Technology, Liaoning, China, 2008.

[29] C. Jichao, Construction and Application of Operational Risk Assessment Model for Oilfield Enterprises Based on Factor Analysis Method, Southwest Petroleum University, Sichuan, China, 2014.

[30] Z. Aimin, H. Wang, and L. Ningning, "Analysis of the factors and formation mechanism of corporate strategic risk," Modern Management Science, vol. 7, pp. 64-65, 2006.

[31] L. Jiequn and Z. Qing, "A review of corporate strategic risk research," Productivity Research, no. 2, pp. 239-241, 2010.

[32] Y. Q. Shang, Research on the identification, evaluation and response of enterprise strategic risk [Ph.D. thesis], Capital University of Economics and Business, Beijing, China, 2011.

[33] Q. Han, L. Chen, and Y. Liu, "Tanzania's oil and gas investment environment," International Petroleum Economics, vol. Z1, pp. 133-139, 2014.

[34] L. Tian, Z. Wang, A. Krupnick, and X. Liu, "Stimulating shale gas development in China: A comparison with the US experience," Energy Policy, vol. 75, pp. 109-116, 2014.

[35] R. E. Ericson, "Eurasian natural gas pipelines: The political economy of network interdependence," Eurasian Geography and Economics, vol. 50, no. 1, pp. 28-57, 2009.
[36] R. J. Pierce, "Reconsidering the Roles of Regulation and Competition in the Natural Gas Industry," Harvard Law Review, vol. 97, no. 2, p. 345, 1983.

[37] B. Quélin and F. Duhamel, "Bringing together strategic outsourcing and corporate strategy: Outsourcing motives and risks," European Management Journal, vol. 21, no. 5, pp. 647-661, 2003.

[38] W. Liu, Research on risk early warning mechanism of natural gas market in XX company [M.S. thesis], Southwest Petroleum University, Chengdu, China, 2016.

[39] Y. Liu, S. Li, and X. Xu, "Researches on risk evaluation models of natural gas industry downstream market," Natural Gas Industry, vol. 26, no. 7, pp. A20-138, 2006.

[40] H. Olin and W. Xiaoming, "Safety of natural gas supply and countermeasures," Natural Gas Industry, vol. 28, no. 10, pp. 125129, 2008.

[41] N. Higashi, Energy Markets and Security Working Papers, IEA Energy Markets and Security Working Papers, 2009.

[42] Y. C. Feng, Research on financial risk control of overseas of $A$ project in J Oilfield [M.S. thesis], China University of Petroleum (Beijing), Beijing, China, 2013.

[43] D. X. Cheng et al., The Theory and Practice of The Financial Analysis and Evaluation of Oil Enterprises, Petroleum Industry Press, 2010.

[44] L. L. Wang, "Problems and Countermeasures in the management of enterprise inventory," Friends of Accountants, vol. 35, pp. 72-73, 2011.

[45] X. Y. Qian, "An analysis of the combination of account receivable turnover and inventory turnover," in Financial and Accounting Monthly: Comprehensive Edition, vol. 7, pp. 80-82, 2012.

[46] K. Padachi, "Trends in working capital management and its impact on firms' performance: an analysis of Mauritian small manufacturing firms," International Review of Business Research Papers, vol. 2, no. 2, pp. 45-58, 2006.

[47] L. M. Hitt, D. J. Wu, and X. Zhou, "Investment in enterprise resource planning: Business impact and productivity measures," Journal of Management Information Systems, vol. 19, no. 1, pp. 71-98, 2002.

[48] M. Baker and J. C. Stein, "Market liquidity as a sentiment indicator," Journal of Financial Markets, vol. 7, no. 3, pp. 271-299, 2004.

[49] P. M. Fairfield and T. L. Yohn, "Using asset turnover and profit margin to forecast changes in profitability," Review of Accounting Studies, vol. 6, no. 4, pp. 371-385, 2001.

[50] K. Kaur and B. Singh, "on-performing assets of public and private sector banks (a comparative study)," South Asian Journal of Marketing \& Management Research, vol. 1, no. 3, pp. 54-72, 2011.

[51] J. McPeak, "Confronting the risk of asset loss: What role do livestock transfers in northern Kenya play?" Journal of Development Economics, vol. 81, no. 2, pp. 415-437, 2006.

[52] J. Jiao, "Study on the index system of evaluating the quality of the listed companies' profit," Enterpriser World, vol. 2, pp. 216217, 2010.

[53] A. M. Qian and X. M. Zhang, "Construction and testing of three-dimensional composite evaluation system of enterprises' financial situation-evidence from China's a share listed companies in manufacturing industry," China Industrial Economics, vol. 276, pp. 88-89, 2011. 
[54] W. Xuxiang, T Lizhong, and L Guoxiang, "Research on enterprise operational risk management," China Market, vol. 1, pp. 48-49, 2008.

[55] W. Wenshuai, "Discussion on enterprise operation cost management and risk control," Technology and Enterprise, vol. 5, p. $16,2012$.

[56] J Xin and Y. Naiding, "The risk study of human resource management," Soft Science, vol. 17, no. 6, pp. 53-55, 2003.

[57] Z. Mingjia, "The warning index system of risk in human resource management," Journal of Xian Institute of Technology, vol. 24, no. 4, pp. 403-406, 2004.

[58] S. Zehou and L. Dongmei, "Risk management in human resource management," Human Resources Development in China, vol. 9, pp. 32-35, 2002.

[59] C. H. Shen, Research on the analysis, evaluation and Countermeasures of human resource risk [M.S. thesis], Wuhan University of Technology, Wuhan, China, 2003.

[60] Y. Dong, "Enterprise material procurement risk and its management prevention," Contemporary Economy, vol. 21, pp. 22-23, 2010.

[61] J. Hui, "How to prevent the risk of material procurement," Financial Management, vol. 6, pp. 62-64, 2005.

[62] Y. Qiu, Identification and control of material purchase risk of overseas of A project [M.S. thesis], East China University of Science and Technology, Shanghai, China, 2016.

[63] H. Tang, "Construction of legal risk and prevention and control mechanism for the long distance pipeline enterprise of natural gas," Oriental Enterprise Culture, vol. 10, pp. 180-183, 2014.

[64] G. Chen, Y. Shuping, G. Qingyu, L. Jian, and X. Ling, "Integrated HSE-risk management mode of long distance transmission pipeline construction projects," Industrial Engineering and Management, vol. 14, no. 5, pp. 129-134, 2009.

[65] L. J. Jiang, Analysis of HSE management system in China's petroleum enterprises [M.S. thesis], China University of Petroleum (Beijing), Beijing, China, 2011.

[66] F. K. Adams, "Construction contract risk management: a study of practices in the United Kingdom," Cost Engineering, vol. 50, no. 1, pp. 22-33, 2008.

[67] J. H. Barton, "The economic basis of damages for breach of contract," The Journal of Legal Studies, vol. 1, no. 2, pp. 277-304, 1972.

[68] A. J. Brito and A. T. de Almeida, "Multi-attribute risk assessment for risk ranking of natural gas pipelines," Reliability Engineering \& System Safety, vol. 94, no. 2, pp. 187-198, 2009.

[69] I. Dincer and M. A. Rosen, "Energy, environment and sustainable development," Applied Energy, vol. 64, no. 1-4, pp. 427-440, 1999.

[70] D. J. Rozell and S. J. Reaven, "Water pollution risk associated with natural gas extraction from the Marcellus Shale," Risk Analysis, vol. 32, no. 8, pp. 1382-1393, 2012.

[71] M. Li, W. Wei, J. Wang, and X. Qi, "Approach to evaluating accounting informatization based on entropy in intuitionistic fuzzy environment," Entropy, vol. 20, no. 6, article 476, 2018.

[72] X. J. Wang, C. P. Wei, and T. T. Guo, "A method to derive experts" weights in intuitionistic fuzzy multi-attribute group decision making based on cross entropy and entropy," Journal of Qufu Normal University (Natural Science), vol. 37, no. 3, 2011. 


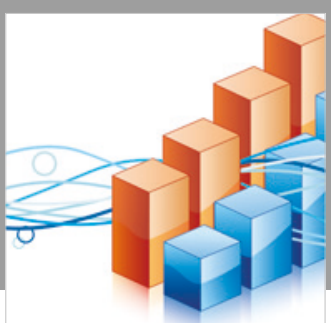

Advances in

Operations Research

\section{-n-m}
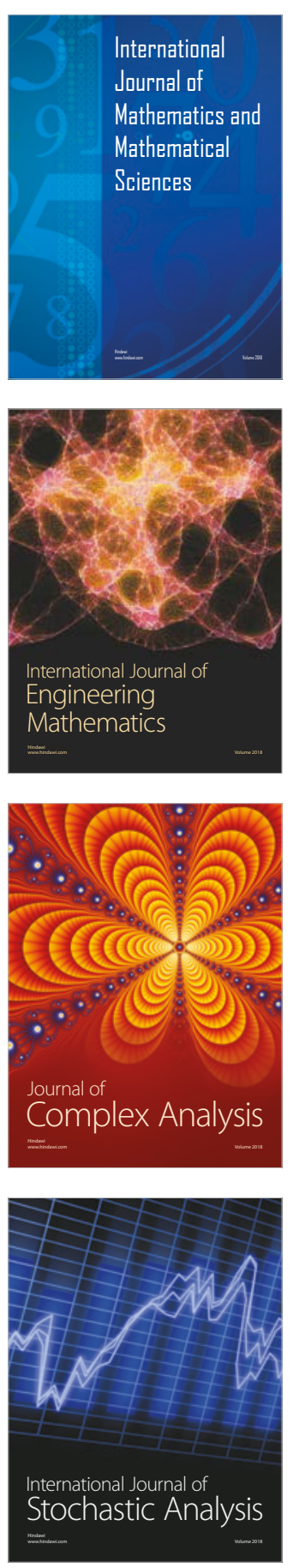
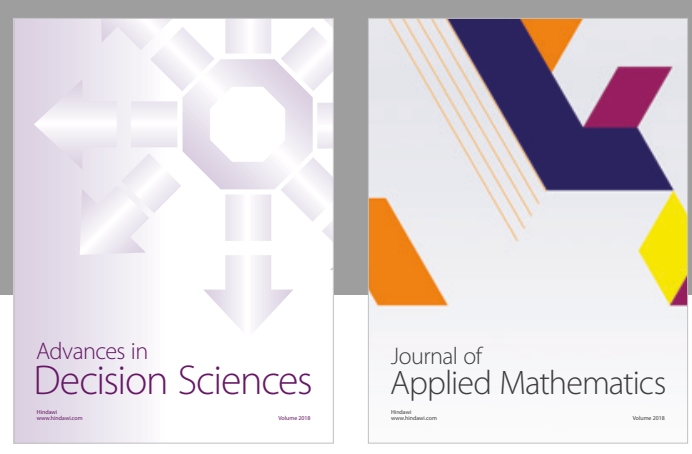

Journal of

Applied Mathematics
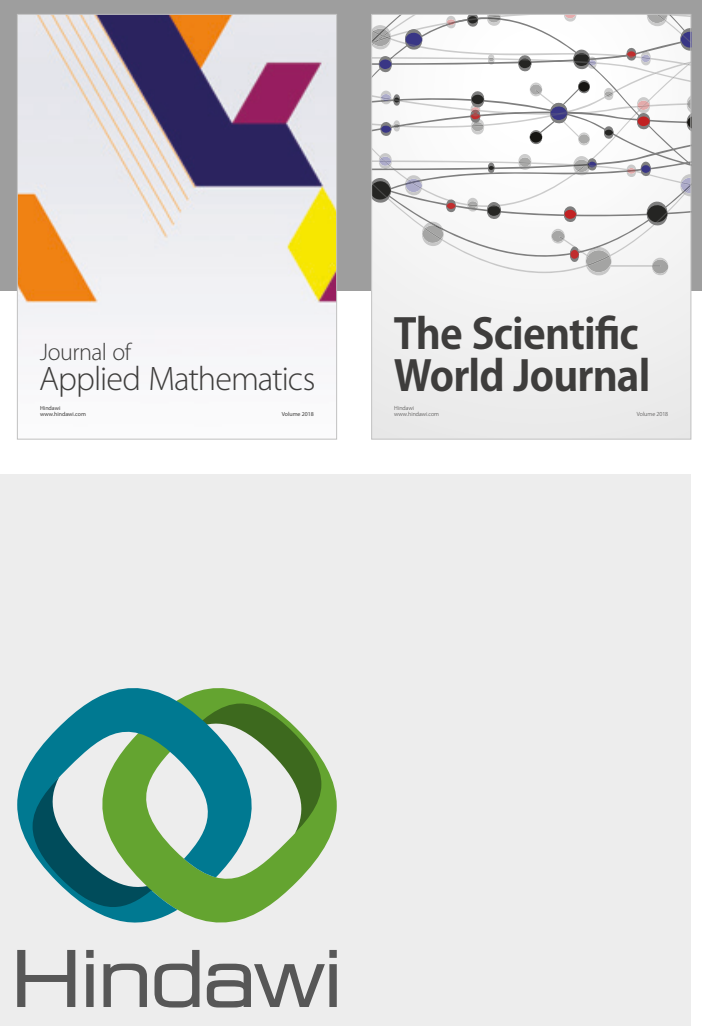

Submit your manuscripts at

www.hindawi.com

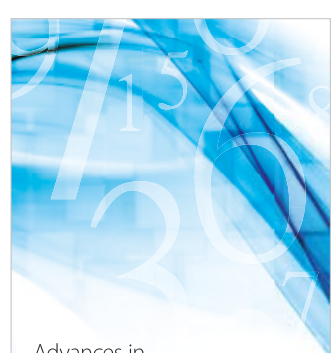

Advances in
Numerical Analysis
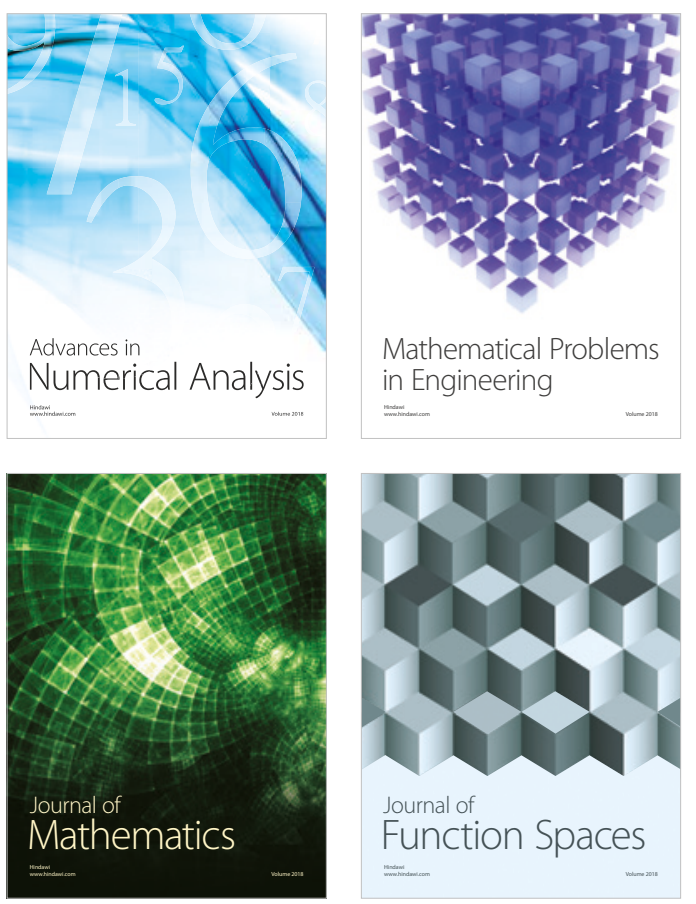

Mathematical Problems in Engineering

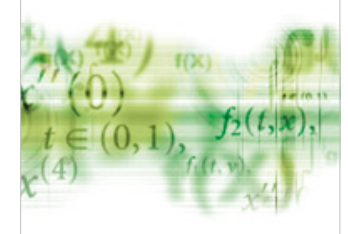

International Journal of

Differential Equations

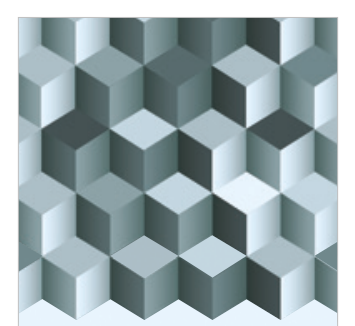

Journal of

Function Spaces

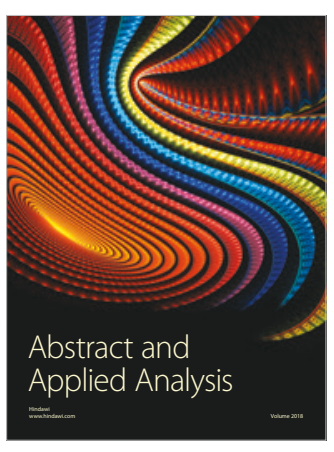

The Scientific

World Journal

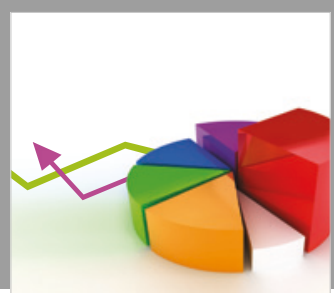

Journal of

Probability and Statistics
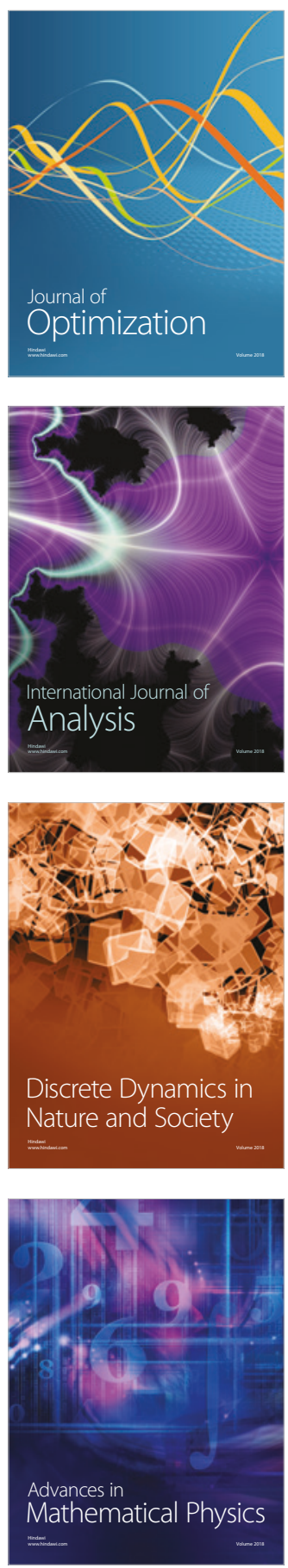